\title{
Benign childhood occipital epilepsy, Gastaut type
}

INSERM

\section{Source}

INSERM. (1999). Orphanet: an online rare disease and orphan drug data base. Benign childhood occipital epilepsy, Gastaut type. ORPHA:98816

Benign childhood occipital epilepsy, Gastaut type is a rare, genetic neurological disorder characterized by childhood to mid-adolescence onset of frequent, brief, diurnal simple partial seizures which usually beg in with visual hallucinations (e.g. phosphenes) and/or ictal blindness and may associate non visual seizures (such as deviation of the eyes, oculoclonic seizures), forced eyelid closure and blinking and sensory hallucinations. Postictal headache is common while impairment of consciousness is rare. 